\title{
ESTUDO ANALÍTICO DE PUBLICAÇÕES SOBRE EAD NA EDUCAÇÃO ESPECIAL COMO FERRAMENTA PEDAGÓGICA
}

\author{
ESTUDIO ANALÍTICO DE PUBLICACIONES SOBRE EAD EN LA EDUCACIÓN \\ ESPECIAL COMO HERRAMIENTA PEDAGÓGICA
}

\section{ANALYTICAL STUDY OF PUBLICATIONS ON EAD IN SPECIAL EDUCATION AS A PEDAGOGICAL TOOL}

\author{
Dulcegleika Villas Boas SARTORI ${ }^{1}$ \\ Lucas Justiniano BERMEJO ${ }^{2}$ \\ Érika Zambrano TANAKA ${ }^{3}$ \\ José Anderson SANTOS CRUZ ${ }^{4}$ \\ Leonel CAPETTI ${ }^{5}$ \\ Larissa Ribeiro FERREIRA ${ }^{6}$
}

RESUMO: O presente estudo teve como objetivo analisar a educação à distância no Brasil e seu uso na educação especial como inclusão escolar. Para tanto foi realizado um estudo e levantamento bibliográfico sobre o assunto em periódicos, revistas científicas nacionais e livros para a presente discussão. Observa-se que a educação à distância é uma modalidade em constante crescimento no Brasil, e as novas tecnologias de informação e comunicação podem contribuir na educação, sendo uma possibilidade de inclusão no processo de ensino e aprendizagem. Entretanto, a inclusão dos sujeitos com alguma deficiência, ainda está acontecendo, pois diante das possibilidades e perspectivas, e dos avanços, requer maior participação dos agentes públicos através de políticas públicas. Para que a educação especial e a inclusão escolar aconteçam de forma efetiva, se faz necessário que o professor possa permanecer na formação continuada, com isso, atender o deficiente nos processos de ensino e aprendizagem, ou seja, o professor educador deve

1 Doutora em Fisioterapia pela Universidade Estadual Paulista Júlio de Mesquita Filho (2010) e especialização em Fisioterapia Pélvica pela Faculdade Inspirar - Londrina (PR) (2016). Atualmente é professora do curso de fisioterapia. E-mail: dulcevb.sartori@gmail.com

${ }^{2}$ Aluno especial de doutorado pelo programa Educação escolar da Faculdade de Ciências e Letras de Araraquara - UNESP (2017) e aluno especial do programa Educação para Ciência da Faculdade de Ciências de Bauru - UNESP em 2016. Mestre em Ciências na área de Microbiologia pela USP em 2012. É professor e coordenador do curso de Ciências Biológicas da Faculdade Anhanguera de Bauru. E-mail: lucasjbermejo@hotmail.com

${ }^{3}$ Professora Doutora da Área de Enfermagem na Saúde da Mulher e do Recém-nascido/FENF UNICAMP. Membro do Grupo de Estudo e Pesquisa da Saúde da Mulher e do Recém-nascido (GEPESM) da Faculdade de Enfermagem. Doutora pela Faculdade de Medicina de Ribeirão Preto da Universidade de São PauloUSP. E-mail: eztanaka@unicamp.br

${ }^{4}$ Doutorando em Educação Escolar pelo PPG - FCLAr/Unesp. Bolsista Capes. Professor e orientador da Pós-graduação Faculdade Anhanguera de Bauru. E-mail: joseandersonsantoscruz@gmail.com

5 Aluno especial do Programa de Doutorado em Engenharia de Produção - Unesp em 2016, Mestre em Agronomia (Energia na Agricultura) pela Faculdade de Ciências Agronômicas da Unesp de Botucatu. Coordenador e Docente dos Cursos Superiores de Tecnologia em Cursos de MBA e Pós-Graduação. Email: leonel.capetti@anhanguera.com

${ }^{6}$ Mestre em Bases Gerais da Cirurgia pela Faculdade de Medicina de Botucatu - UNESP (2016). Coordenadora do curso de fisioterapia da Faculdade Anhanguera de Bauru. E-mail: larissa_rf_1903@hotmail.com 
estar em constante aprendizado. A educação à distância tem se mostrado uma alternativa com bons resultados na formação do professor da educação especial. Porém, diante do levantamento, observamos que não há relatos do uso da $\mathrm{EaD}$ como possibilidade na educação especial para acesso e inclusão dos sujeitos com alguma deficiência, mas para a formação inicial e continuada do professor e educador a EaD tem sido utilizada como meio possível para alcançarmos profissionais com mais habilidades e competências na educação especial.

PALAVRAS-CHAVE: Educação à distância. Educação especial. Brasil.

RESUMEN: El presente estudio tuvo como objetivo hacer un análisis de la educación a distancia en Brasil y su uso en la educación especial y en la inclusión escolar. Por tanto, fue realizado un estudio y levantamiento bibliográfico acerca del asunto en periódicos, revistas científicas nacionales y libros para la discusión. Se observa que la educación a distancia es una modalidad en constante crecimiento en Brasil, y que las nuevas tecnologías de información y comunicación pueden contribuir en la educación, siendo una posibilidad de inclusión en el proceso de enseñanza y aprendizaje. Entretanto, la inclusión de los sujetos con alguna discapacidad aún está ocurriendo, pues delante de las posibilidades y perspectivas, y de los avances, requiere mayor participación de los agentes públicos a través de políticas públicas. Para que ocurra la educación especial y la inclusión escolar de manera efectiva, se hace necesario que el profesor esté capacitado para atender al alumno con deficiencia de manera adecuada, es así que el profesional tiene que estar en un constante aprendizaje. La educación a distancia se ha mostrado como una alternativa con buenos resultados en la capacitación del profesor de educación especial. Sin embargo, delante del levantamiento, observamos que no hay relatos del uso de la EaD como posibilidad en la educación especial para el acceso e inclusión de los sujetos con alguna discapacidad, pero para la formación inicial y continuada del profesor y educador, la EaD ha sido utilizada como medio posible para que alcancemos profesionales con más habilidades y competencias en la educación especial.

PALABRAS-CLAVE: Educación a distancia. Educación especial. Brasil

ABSTRACT: This study aimed to analyze distance learning in Brazil and its use in special education as school inclusion. For this, a study and a bibliographic survey on the subject were carried out in periodicals, national scientific magazines and books for the present discussion. It is observed that distance learning is a modality in constant growth in Brazil, and the new information and communication technologies can contribute to education, becoming a possibility of inclusion in the teaching and learning process. However, the inclusion of subjects with some deficiency is still happening, because before the possibilities and perspectives, and the advances, it requires greater participation of the public agents through public policies. In order for special education and school inclusion to take place in an effective way, it is necessary for the teacher to be able to remain in a continuous formation, thereby attending to the disabled in the teaching and learning processes, that is, the teacher must be in constant learning . Distance learning has proved to be an alternative with good results in the education of the special education teacher. However, according to the survey, we observed that there are no reports of the use of distance learning as a possibility in special education for access and inclusion of subjects with some disability, but for the initial and continued formation of distance 
learning teacher and educator, it has been used as a possible means to professionals with more skills and competences in special education.

KEY WORDS: Distance learning. Special education. Brazil.

\title{
Introdução
}

A EaD é uma realidade mundial em constante crescimento; pois, esse crescimento darse-á devido às necessidades na gestão do tempo do estudante, tornando-se nicho da educação para o ensino mediado por computadores com o uso da internet, chats e fóruns de discussões. Além de minimizar as distâncias territoriais, dando acesso às mais diversas culturas e territórios mediante a rede. A evolução dessa modalidade possibilita ao estudante e professores a flexibilidade dos estudos.

Os cursos em EaD apresentam para o profissional já inserido no mercado de trabalho relevância para os que buscam gerir tempo e espaço, pois estas facilidades são apenas detalhes quando o meio de comunicação é mediado pelo computador. Sendo as Tecnologias de Informação e Comunicação (TICs) um meio e com possibilidades de interação na formação do sujeito (MORAM, 2009). Com isso,

\begin{abstract}
Deve-se ressaltar que a EaD representa a possibilidade de ampliação do cenário do ensino superior, compreendendo a multiculturalidade e a diversidade de contextos em que é inserida e, oportunizando assim, o acesso à educação em favor de um público que subscreve o fato de que a EAD passa a representar a escolha de "muitos"; inclusive, daqueles que teriam a possibilidade de optar pelo ensino presencial. Neste aspecto, a EAD fica entre o "limite" e/ ou "fronteira" sobre o que até então era um processo de descoberta no ensino e, passa a representar a opção de um público cada vez maior nas instituições de ensino superior (COSTA; ALVES, 2014, p. 212).
\end{abstract}

Nesse sentido, a educação especial, conforme o Art. 58, de 20 de dezembro de 1996, é uma modalidade de educação escolar na rede regular nacional que atende crianças com necessidades especiais, incluindo o acesso a um ensino de qualidade por meio de materiais, recursos pedagógicos específicos e profissionais especializados (BRASIL, 1996).

Sabendo que a inclusão escolar é obrigatória e está embasada por leis e diretrizes pelo Ministério da Educação, uma parceria bem estabelecida deve existir entre as áreas da Educação, da Saúde e da Assistência Social para a construção de propostas educativas que melhor 
respondam às necessidades específicas das crianças e de seus familiares nas diferentes regiões do país.

As instituições escolares e as políticas públicas devem se modificar e encontrar formas de educar os sujeitos, além de incentivar e participar nas modificações das atitudes discriminatórias e na construção de sociedades acolhedoras e inclusivas onde se acentuem as potencialidades das pessoas com deficiências e/ou impedimentos educacionais, e que a aprendizagem se adapte as necessidades desses educandos, em vez de serem eles que devam se adaptar a concepções predeterminadas. A partir desta reflexão, é possível observar que,

\begin{abstract}
A inclusão escolar a partir dessas Declarações começou a ganhar forma e iniciou-se a disseminação de seus ideais em vários países. As reformas educacionais promovidas a partir da década de 1990, pelos organismos internacionais, cooperaram para que a inclusão fosse pensada como resposta para escolarizar alunos considerados diferentes em relação ao público-alvo comumente atendido na escola (SILVA; CARNEIRO, 2016, p. 936).
\end{abstract}

A inclusão escolar é um processo benéfico para toda a sociedade, uma vez que visa proporcionar os sujeitos com deficiência oportunidades iguais, e estimula e os sujeitos sem deficiência para o convívio com outros com deficiências. Desta forma contribui para que a nossa sociedade se torne menos preconceituosa através da educação inclusiva.

A educação tem por objetivo promover o acesso à informação e ao conhecimento - a educação formal e informal possuem possibilidades de interação e interação em diversas culturas, modos de vida como também relações mediante o meio em que o sujeito vive -, e com isso desenvolver as habilidades e competências no/do sujeito. Pois, os atores sociais envolvidos nesse processo fazem parte de um contexto social e cultural. Para isso ocorrer se faz necessário que todos que estão inseridos nessa jornada tenham acesso às informações inseridas aos Projetos Políticos Pedagógicos de cada instituição. Assim, compreender que a educação inclusiva não é somente incluir o sujeito - educandos e atores sociais, profissionais da educação - mas envolver a sociedade como um todo, além disso, ter o conhecimento sobre as questões políticas e educacionais no que envolvem a educação inclusiva.

O professor e educador, torna-se aliado para que isso aconteça, e ao ser mediador, tornase protagonista para a inclusão social, educacional e interação entre os estudantes. Sendo assim, a formação dos mesmos é uma etapa importante para que esse processo alcance seus objetivos. E a modalidade $\mathrm{EaD}$ é um recurso facilitador e contribui com o profissional ativo que pretende aumentar seus conhecimentos, somado à atual facilidade de acesso às TICs. 
Utilizou-se como método a revisão de literatura, de acordo com Koller, Couto e Hohendorff (2014), na qual afirmam que a produção de revisões de literatura faz parte do cotidiano da pesquisa, sendo necessário abordar de forma reflexiva e crítica materiais já publicados. Nesse método, é parte relevante o esclarecimento dos ARL (Artigos de Revisão de Literatura) sumarizar um determinado objeto de estudo, a fim de esclarecer e mostrar pontos fundamentais das pesquisas revisadas. Foram analisados artigos de bases de dados nacionais, publicados no período de 2002 a 2017.

Os textos foram analisados quanto as possibilidades da EaD na educação especial, a formação do sujeito e a inclusão dos sujeitos com alguma deficiência na educação escolar mediada pelas TICs. Para a escolha dos textos utilizou-se os filtros de busca através de palavraschave - EaD, Inclusão Escolar, TICs e Educação Especial, Formação continuada do professor para a educação especial. Em seguida buscou-se através da leitura dos resumos um panorama para a construção desta.

Foi baseado nos achados e considerações - levantamento bibliográfica mediante as produções que este estudo foi desenvolvido -, com o intuito de apresentar o desenvolvimento da EaD no Brasil e elucidar a relevância da Educação Especial, verificando a correlação e uso da EaD na Educação Especial. A partir do levantamento, a construção do desenvolvimento e das discussões deste artigo, deu-se por discutir e apontar com citações indiretas e diretas, pois trata-se de um estudo focado em análise de produções cientificas publicadas. Por fim, as considerações finais pautadas diante do levantamento e das pesquisas relacionadas.

Entretanto, foi possível observarmos que a EaD é crescente e sua demanda está diante das possibilidades existentes quanto ao acesso pela gestão de tempo do estudante. E a inclusão do sujeito com alguma deficiência no Brasil pela educação está em andamento, mas requer mais atitudes por parte dos atores públicos. No que tange no uso da $\mathrm{EaD}$ na educação especial não houve relatos, tornando uma possibilidade de investigação com mais amplitude e possibilidades de políticas públicas.

\section{A Educação à Distância no Brasil}

Educação à distância é o processo de ensino-aprendizagem mediado por tecnologias, onde professores e educandos estão separados espacial e/ou temporalmente. Pois, "A Educação a Distância (EaD) tornou-se uma possibilidade de formação ou educação continuada no Brasil, especialmente quando se trata de temas pouco abordados nos cursos de graduação" (LEMES, 
MAIA, YAMAUTI, 2015, p. 106). Tal modalidade tem estado em constante crescimento devido a facilidade de acesso às tecnologias de comunicação - embora ainda é possível verificar que existem regiões que não possuem acesso as tecnologias, principalmente ao acesso e apropriação da rede mundial de computadores-, em especial a rede mundial de computadores. Mas, é fato que ao debruçarmos na EaD, observamos que, “A educação a distância tem expandido seus horizontes nas duas últimas décadas, principalmente quanto às possibilidades de acesso [...] e também aos cursos de formação continuada, após a etapa inicial de formação (graduação) " (CARDOSO et al, 2016, p. 1390).

Nessa vertente, ou seja, na formação continuada, as atuais tecnologias de informação permitem um alto poder de interação entre aluno e professor, assim como alunos colegas do mesmo curso ou disciplina ofertada à distância (MORAM, 2008; MUGNOL, 2009). Nesse contexto, pode-se afirmar que,

Se entendermos as tecnologias como favorecedoras da produção e disseminação de imagens, podemos pensá-las como um campo fértil onde circulam nossos modos de ver, e onde também aprendemos a tomar um posicionamento no espaço e no tempo em que vivemos (GARLET; MINUZZI, 2014, p. 150).

E ao tomarmos conhecimento e termos o nosso posicionamento no espaço, observamos relatos em alguns estudos, no qual citam as cartas do apóstolo Paulo, enviadas aos Cristãos da época, com instruções de como proceder dentro das doutrinas Cristãs, por volta do século I, como um marco histórico do início da Educação à distância no mundo. Contudo, a Educação à distância passou a existir institucionalmente no século XIX, com o uso da correspondência como meio de transmissão de informação e instrução aos educandos. Nesse olhar, pode-se dizer que,

\begin{abstract}
A EaD é modalidade pressupõe uma redefinição de papeis, a educação passa do processo transmissor-emissor para um processo de conhecimento compartilhado. $\mathrm{O}$ aluno passa a ter um maior envolvimento com o processo de ensino aprendizagem, deve ser o gestor do próprio tempo, requer organização e principalmente disciplina. Essa quebra de paradigmas do modelo tradicional ainda é muito forte, assim é necessário que esse modelo ofereça recursos e ferramentas que crie um ambiente motivador e colaborativo para a construção compartilhada do conhecimento (VOLPATO; SANTOS CRUZ, 2016, p. 2).
\end{abstract}

Ao redefinir os papéis, a educação através do processo de ensino e aprendizagem, observa-se que algumas instituições passaram a adotar o ensino por correspondência no mundo, 
e com o avanço dos meios de comunicação, o rádio e a televisão também passaram a ser usados como meio de ensino (ALVES, 2011; MUGNOL, 2009).

Essa modalidade foi usada para tornar a educação convencional acessível às pessoas residentes em áreas isoladas ou àqueles que não tinham condições de cursar o ensino regular no período apropriado, sendo considerada uma educação de baixo custo e até mesmo de segunda classe, mas observa-se que,

Na Educação a Distância, composta por equipes multidisciplinares, os profissionais devem apresentar ou desenvolver alguns conhecimentos, habilidades e atitudes (CHA) inerentes a esta modalidade, que de certa forma diferencia-se um pouco da modalidade presencial (SANTOS; ALMEIDA, 2017, p. 348).

Nessa multidisciplinaridade e interdisciplinaridade na $\mathrm{EaD}$, os avanços das tecnologias, a Educação à distância passaram a ser disseminadas, favorecendo o acesso à educação em diferentes níveis, trazendo benefícios a um grande número de estudantes. Assim como também ganhou uma nova perspectiva com o uso das Tecnologias de Informação e Comunicação (TICs), devido à sofisticação, rapidez na distribuição dos conteúdos e melhor interação entre os envolvidos (MUGNOL, 2009).

No Brasil, os primeiros registros de Educação à distância datam do século XX. Em 1904, o Jornal do Brasil anuncia em seus classificados profissionalização para datilógrafos por correspondência. A partir daí vários cursos por correspondência começaram a ser ofertados, como também pelo rádio e TV. Nesse contexto, surgiram grandes institutos especializados em educação à distância, como o instituto Monitor, Instituto Universal Brasileiro, Universidade do Ar, responsáveis pelo atendimento de vários alunos em cursos profissionalizantes à distância (ALVEZ, 2011)

Vários são os conceitos dados a educação à distância ao longo dos anos - decidiu-se não apontar os conceitos, pois não é o foco deste estudo, no entanto, temos como principal para a discussão o conceito da EaD no Brasil, este definida oficialmente no Decreto 5.622, de 19 de dezembro de 2005 (BRASIL, 2005):

Artigo $1^{\circ}$. Para os fins deste Decreto caracteriza-se a educação à distância como modalidade educacional na qual a mediação didáticopedagógica nos processos de ensino e aprendizagem ocorre com a utilização de meios e tecnologias de informação e comunicação, com estudantes e professores desenvolvendo atividades educativas em lugares ou tempos diversos. 
O parágrafo primeiro do mesmo artigo ressalta a obrigatoriedade de momentos presenciais para: avaliação dos estudantes; estágios obrigatórios, quando previstos na legislação pertinente; defesa de trabalhos de conclusão de curso, quando previstos na legislação pertinente; e atividades relacionadas a laboratórios de ensino, quando for o caso.

Segundo o Artigo $2^{\circ}$, a educação à distância poderá ser ofertada na educação básica (nos termos do art. 30 do mesmo decreto); educação de jovens e adultos; educação especial, respeitadas as especificidades legais e pertinentes; educação profissional, abrangendo os cursos de nível técnico e tecnólogo de nível superior; curso superior, abrangendo cursos sequenciais, de graduação, de especialização, de mestrado e de doutorado (BRASIL, 2005).

A regulamentação da Educação à distância deu-se no ano de 1996, com a Lei 9.394 de 20 de dezembro do mesmo ano, em seu artigo 80, autorizando a Educação à Distância como modo de ensino. Nesse mesmo ano foi criada a Secretaria de Educação à Distância do MEC. No ano de 2004 portarias autorizaram o uso de disciplinas semipresenciais em até $20 \%$ da carga horária dos cursos superiores reconhecidos, assim como a regulamentação do processo de credenciamento de instituições de ensino para o uso regular da Educação à Distância. Chegamos então na Lei de Diretrizes e Bases, no Decreto 5.622, de 19 de dezembro de 2005, havendo assim o processo de credenciamento de instituições de ensino para o uso regular da Educação à Distância, e por fim o Decreto N. ${ }^{\circ}$ 6.303, de 12 de dezembro de 2007, altera dispositivos dos Decretos nos 5.622, de 19 de dezembro de 2005, que estabelece as diretrizes e bases da educação nacional, e 5.773, de 9 de maio de 2006, que dispõe sobre o exercício das funções de regulação, supervisão e avaliação de instituições de educação superior e cursos superiores de graduação e sequenciais no sistema federal de ensino. (BRASIL, 1996; BRASIL, 2005; CAMACHO, 2009).

As modalidades de educação existentes atualmente são presenciais, semipresenciais e à distância. Existem instituições especializadas que oferecem apenas a modalidade à distância, como a Open University da Inglaterra ou a Universidade Nacional à Distância da Espanha, assim como existem instituições que oferecem modalidades presenciais e à distância ao mesmo tempo, sendo estas a maior parte. No Brasil este último modelo predomina (MORAM, 2008).

Anteriormente, via-se a educação à distância como uma atividade complementar a educação presencial. Muito utilizada por instituições públicas como forma complementar ao ensino, essa modalidade passou a ser um objeto importante na disputa do mercado educacional em se tratando das instituições privadas, que passaram a fazer uso da educação à distância (GIOLO, 2008). 
A partir do ano de 2002, a iniciativa privada também passou a se credenciar para oferecer a Ead, que anteriormente era oferecida por instituições públicas inicialmente com o intuito de capacitar os professores da rede pública por meio de cursos complementares. Essa modalidade passou a ter uma atuação especial na educação superior, apesar da LBD de 1996 descrever o uso da Ead em todos os níveis de educação, sendo assim o foco dos legisladores da época (GIOLO, 2008; BELLONI, 2002).

Cursos ministrados em sua totalidade à distância passaram a substituir cursos presenciais, e isso está intimamente ligado à percepção das instituições em relação a diminuição da demanda financeira para bancar a educação presencial, relativamente de alto custo quando comparada à educação à distância (GIOLO, 2008)

Hoje é possível presenciar um investimento na Educação à distância, seja pela iniciativa privada de ensino que encontrou nessa modalidade um ótimo mercado para investimento, seja por instituições públicas de ensino, que estão aderindo à ênfase do governo em formar professores por meio dessa modalidade, com isso,

\begin{abstract}
Ao ter como pressuposto inicial que os professores se tornem autores argumentativos, reflitam e contextualizem sua prática pedagógica cotidiana deve-se investir num projeto de concepção de formação docente que supere a dicotomia entre teoria e prática, tendo como eixo o desenvolvimento de novas competências, que se definem como a capacidade de mobilizar múltiplos recursos numa mesma situação, para responder às diferentes demandas das situações de trabalho (TEZANI, 2014, p. 52).
\end{abstract}

E dessa forma, atualmente, a política nacional de formação de professores adota a Educação à distância como uma modalidade possível e acima de tudo para suprir a defasagem de professores de nível superior. Isso tem resultado na penetração da educação à distância em diversos contextos educacionais (LAPA; BELLONI, 2012).

Para alguns autores, a educação à distância é imprescindível para modificar processos insuficientes e caros de ensinar ao longo da vida, principalmente por conta da flexibilidade que essa modalidade oferece, não exigindo que o aluno esteja em tempo e espaço específico para que o aprendizado aconteça; apesar do preconceito ainda existente em relação a essa modalidade de ensino, julgada por muitos profissionais insuficiente para o aprendizado, para muitos devido ao afastamento entre os envolvidos, assim como a falta de cobrança ao aluno em relação aos estudos que não se encontra tão presente como na educação presencial (MORAM, 2009). 
Atualmente, no Brasil e no mundo, a modalidade à distância é bastante utilizada devido aos avanços tecnológicos alcançados até o momento em vários níveis, médio, técnicos, profissionalizantes, superiores, seja ela como complemento ao ensino presencial, seja na sua totalidade à distância. Vale ressaltar que com as ferramentas tecnológicas atuais, a "distância" entre aluno e professor/tutor se torna cada vez menor, contudo, é de extrema importância haver interação entre os mesmos, assim como atenção do professor/tutor ao aluno, para que o afastamento tempo/espacial não se torne uma barreira para um bom aprendizado por meio da educação à distância.

\title{
A tecnologia nas escolas
}

As tecnologias estão cada vez mais conquistando os muros das escolas e das universidades - mas como dito anteriormente, ainda há espaços que não possuem acesso as tecnologias. E na rede pública de ensino essa invasão se dá por meio das Políticas Públicas de Inclusão Digital, que preveem o repasse de computadores às escolas por meio de diversos programas. Essa conquista faz com que o professor enfrente um novo desafio:

\begin{abstract}
O homem busca incessante descobrir, dominar e encontrar, e tem feito isso com o uso das tecnologias na busca por melhoria das suas condições de vida, o que resulta num processo de aprimoramento constante. As tecnologias, estão hoje permeadas pela cibercultura, a qual, permite a interação num processo contínuo, rico e insuperável que disponibiliza a construção criativa e o aprimoramento constante num movimento de novos aperfeiçoamentos (TEZANI, 2014, p. 50).
\end{abstract}

E na busca por essas melhorias, a principal preocupação dos professores está em como essa tecnologia será incorporada em sua prática pedagógica de forma significativa, e não apenas como mais uma ferramenta para motivar a sua aula ou transmitir conteúdos. Mas observa-se que nessa constante busca por melhorias,

\begin{abstract}
A EaD é uma modalidade de ensino que está em constante remodelação, ora pelas tecnologias que surgem, ora pelas novas dinâmicas de aprendizagem, ora pelas demandas de mercado. Faz-se então necessário analisar constantemente se os modelos ofertados estão atendendo a sua finalidade com eficácia (VOLPATO; SANTOS CRUZ, 2016, p. 12).
\end{abstract}

Mas nessa remodelação, algumas escolas e universidades já dispõem de tecnologias como TV, vídeo, DVD, retroprojetores, projetor de multimídia e laboratórios conectados à internet. Outras, porém, utilizam apenas a tecnologia mais antiga, o quadro negro e o giz, porém 
"[...] as tecnologias sozinhas não mudam a escola, mas trazem mil possibilidades de apoio ao professor e de interação com e entre os alunos" (MORAN, 2003).

A incorporação das tecnologias pela escola deve ser uma preocupação e uma ação de Política Pública de investimentos nessa área, e nesse contexto o Brasil tem avançado no tocante à pesquisa universitária e às políticas atuais. Atualmente, o PROINFO é o programa nacional de maior destaque na área de tecnologia na Educação, pois é o responsável pela distribuição de computadores e periféricos para escolas de todo país, além da criação e implementação dos Núcleos de Tecnologia Educacional (NTEs) em todos os Estados da Federação.

\begin{abstract}
O ritmo com o qual as inovações tecnológicas vêm ganhando espaço na sociedade moderna provoca uma intensa necessidade do ser humano educar-se para as mediações que se constroem entre os conteúdos que desenham as profissões e o ambiente vivido pelas organizações modernas. Novas habilidades, novos significados e constantes rupturas no campo dos valores éticos que conformam o mundo do trabalho desenham a estrutura que rege as organizações, particularmente aquelas que estão voltadas ao setor público estatal (BIZELLI; CUNHA DARIDO, 2013, p. 513).
\end{abstract}

Existe hoje uma discrepância entre as escolas particulares e escolas públicas. As escolas da rede particular de ensino têm absorvido bem as novas tecnologias, mas ainda requer um olhar aprofundado, pois é possível questionar se o uso dessas tecnologias estão à favor do ensino e aprendizagem e da formação do sujeito com reflexão e criticidade. As mesmas fazem convênios com empresas que oferecem serviços de Tecnologia Educacional com os profissionais das mais diversas áreas que acrescentem em seus planos de ensino o uso de tais ferramentas. O que não ocorre na rede pública, já que o problema está justamente na falta de investimentos substanciais, não apenas em equipamentos, mas em formação continuada dos profissionais da educação para utilizarem efetivamente os recursos tecnológicos.

Os estudantes, em sua maioria, dominam a utilização dessa ferramenta, mas isso não acontece com os professores, que continuam estagnados quanto ao uso de recursos tecnológicos no processo de ensino e aprendizagem (CANTINI et al., 2006; DOWBOR, SACHS; LOPES, 2010).

Daí a importância da preparação e interação entre escola, aluno e professor. Segundo Demo, 2005: "parece evidente a dificuldade de transformar as tecnologias em oportunidades de aprendizagem sem a mediação do professor. Qualquer artefato técnico implantado na escola só frutifica sob a mediação do professor”" 


\section{A educação especial no Brasil}

A educação especial no Brasil ainda se encontra em evolução: a mesma passou da exclusão dos estudantes com deficiência em instituições especializadas com finalidades terapêuticas, atingindo propostas de uma escola para todos, única e aberta às diferenças, começando assim os processos de inclusão (MANTOAN, 2006).

Anteriormente, pessoas com deficiência eram em sua maioria consideradas ineducáveis. Havia preconceito em relação às pessoas portadoras de alguma necessidade especial. A partir do século XVI, alguns médicos e pedagogos acreditavam que era possível ensinar estes que até então eram considerados ineducáveis, desafiando conceitos existentes na época. Contudo, estas experiências ainda aconteceram de forma institucionalizada, pois se acreditava que o portador de deficiência era melhor protegido, cuidado e educado se separado do resto da sociedade (MENDES, 2006). Nesse sentido, destaca-se "A partir da década de 1990, o Brasil, seguindo as políticas internacionais, passou a adotar medidas para transformar o sistema de ensino em um sistema que atendesse a todos" (FACHINETTI et al, 2016, p. 864).

No Brasil, a história da educação especial é dividida em três períodos, o primeiro marcado pela participação da iniciativa privada. Nesse período enfatizou-se o atendimento clínico especializado, contudo, com a educação escolar incluída, nessa época surgiram as instituições que primavam pelo atendimento às pessoas com deficiências física, mental e sensorial de forma assistencial, ainda acreditando na maneira segregativa, fazendo com que a educação das pessoas com deficiência acontecesse em um mundo à parte. O segundo período foi definido por ações oficiais no âmbito nacional, onde a educação especial foi assumida pelo poder público em 1957, e o terceiro caracterizado pelos movimentos em favor da inclusão escolar, a partir da década de 1990 (MANTOAM, 2006).

A educação é um direito de todos, independente das diferenças existentes entre um indivíduo e outro; este é um direito garantido legalmente como pontua o artigo 205 da Constituição Federal de 1988 (BRASIL, 1988):

Art. 205. A educação, direito de todos e dever do Estado e da família, será promovida e incentivada com a colaboração da sociedade, visando ao pleno desenvolvimento da pessoa, seu preparo para o exercício da cidadania e sua qualificação para o trabalho.

A partir da Constituição de 1988, é possível observar uma onda de reforma no sistema educacional brasileiro, que traz consigo uma série de ações realizadas sob a justificativa da 
necessidade de alcançar a equidade, o acesso a todos à escola e a qualidade de ensino (MENDES, 2010).

Nos anos de 1990 e 1994, respectivamente, a Declaração Mundial de Educação para Todos e a Declaração de Salamanca tornaram-se marcos importantes relacionados à inclusão escolar, ao traçar metas e sugestões para atender os portadores de necessidades especiais; a partir desse momento o Brasil comprometeu-se a promover inclusão de alunos com necessidades especiais no ensino regular (ALMEIDA, 2008).

\begin{abstract}
A Lei de Diretrizes e Bases da Educação Nacional (BRASIL, 1996) destaca que o sistema educacional assegurará aos alunos com necessidades educacionais especiais currículos, métodos, recursos e organizações pertinentes para responder as suas necessidades. Por sua vez, a Política Nacional de Educação Especial na Perspectiva da Educação Inclusiva (BRASIL, 2008) aponta que a Educação Especial é uma modalidade de ensino que perpassa todos os níveis de ensino, com a oferta de atendimento educacional especializado (AEE), por meio da disponibilização dos recursos e serviços destinados ao suporte ao processo de escolarização de alunos com deficiências, transtornos globais do desenvolvimento (TGD) e altas habilidades/superdotação, que constituem o público-alvo da Educação Especial (FACHINETTI et al, 2016, p. 862).
\end{abstract}

Para Kassar (2012), a atuação da legislação brasileira, que assume para si a responsabilidade de atendimento a estudantes com necessidades especiais e privilegia o atendimento desses educandos em escolas comuns públicas, fazendo com que aconteça incorporação e efetivação dos direitos das pessoas com deficiência no país, seja pela adesão de acordos internacionais, seja pela luta de grupos organizados pela sociedade civil, é um avanço quando se trata de educação especial e inclusão escolar. No entanto,

Está claro que a proposta da educação inclusiva é oferecer um ensino de qualidade a todos de forma equânime. Percebe-se que a sociedade, ainda que em passos lentos, tem buscado atender as demandas de pessoas com necessidades especiais. Sob a compreensão de que tais demandas precisam ser atendidas, em prol da educação de qualidade, $o$ ensino, no Brasil, precisa ultrapassar metas como a de acesso e garantia de vagas e atingir possibilidades reais de desenvolvimento dos indivíduos com necessidades educacionais especiais, de forma que a escola seja inclusiva e ofereça condições de igualdade no acesso às mais diferentes oportunidades disponíveis nos diferentes contextos educacionais (FACHINETTI et al, 2016, p. 865-866).

Sabemos que a inclusão escolar não é apenas colocar um aluno portador de necessidades especiais em uma sala de aula de ensino regular, é necessária a adequação do ambiente e dos profissionais envolvidos nesse processo. Manter fisicamente o aluno portador de necessidades 
especiais para que ele seja considerado igual aos demais sem dar a ele as condições necessárias para que aprenda, recebendo uma educação de qualidade mesmo portando dificuldades, é excluí-lo.

Em nível mundial, a inclusão é entendida como uma reforma educacional profunda e significativa, na qual não se pode tratar apenas de alterações no currículo ou facilitar o acesso de todos, indiscriminadamente (CARAMORI, 2016, p. 1035).

O professor pode e deve identificar e reconhecer as necessidades especiais de seus estudantes, mas não é de sua responsabilidade, mas de toda a equipe educacional da instituição, seja pública ou privada, assim como proporcionar atividades que os motivem no ambiente e facilitem a interação com os sujeitos ditos normais e com o próprio professor. Assim, observamos a necessidade de um profissional preparado para atuar na educação especial e inclusão escolar (ALMEIDA, 2008).

As dificuldades enfrentadas por cuidadores na inclusão escolar da criança com paralisia cerebral (ARAÚJO; LIMA, 2011) mostram que a falta de formação dos professores, o despreparo físico das escolas e a falta de um estagiário, a falta de materiais adaptados, assim como a dificuldade de acesso à escola e a falta de transportes adaptados são fatores que dificultam a inclusão e,

O processo de formação do professor, seja ela inicial ou continuada, está intrinsecamente ligado a essas rupturas e mudanças de postura e de prática que a inclusão exige, pois é um dos pilares do seu desenvolvimento profissional, refletindo diretamente no trabalho em sala de aula e nos resultados com os alunos (CARAMORI, 2016, p. 1037).

Podemos dizer que a inclusão é um grande desafio, por depender de vários aspectos, no âmbito social e escolar, para que aconteça.

Luiz e Nascimento (2012) buscaram explorar as experiências das famílias no processo de inclusão das crianças com Síndrome de Down; levantaram em seus estudos pontos relevantes, como receio das mães à troca de uma instituição especializada para uma instituição de ensino regular, a dúvida em relação à hora certa de realizar essa transição, assim como a recusa de algumas mães a colocar o filho em uma escola regular de ensino e também o medo do preconceito por parte dos estudantes da escola regular. Estes achados nos mostram que muitos paradigmas ainda precisam ser quebrados quando se trata de inclusão escolar. 
Primordial é organizar toda a Escola para poder dar resposta às necessidades de qualquer tipo de cidadão através de projeto estratégico de atendimento, o qual permita organizar recursos e formas de atuação, evitando a improvisação e dando segurança à equipe que trabalha na Escola, como um todo, e aos professores, de forma particular. Fortalece a gestão escolar poder contar com um quadro habilitado de profissionais que possam atuar em laudos diagnósticos, principalmente se esses profissionais estiverem articulados em equipes técnicas, das quais a coordenação de atendimento para crianças e adolescentes com deficiência ou com dificuldades específicas seja membro efetivo (MATTOS; BIZELLI, 2016, p. 1069).

A educação especial por meio da inclusão escolar ainda é um grande desafio, apesar dos avanços ocorridos com o passar dos anos. Não basta juntar pessoas com deficiência às pessoas consideradas “normais", é preciso estar preparado em para que esse processo aconteça de forma efetiva.

\begin{abstract}
A prática pedagógica inclusiva, aquela que responde às necessidades variadas dos alunos, precisa ser construída, não sabemos trabalhar com todos os alunos porque historicamente a escola selecionou $\mathrm{e}$ homogeneizou o grupo de educandos e seus modelos pedagógicos. Finalizando, é preciso criar uma cultura de colaboração, envolvendo professores comuns, professores especializados, gestão da escola, família, parceiros da comunidade, enfim, todos os recursos humanos capazes de oferecer à escola e aos alunos condições plenas de desenvolvimento (CARNEIRO; UEHARA, 2016, p. 932).
\end{abstract}

Enfatizamos a capacitação do professor, assim como o preparo da instituição de ensino regular para receber esses alunos.

\begin{abstract}
Outra discussão importante acerca da formação e da prática docente é a da dicotomia entre teoria e prática que precisa ser superada. A relação entre a teoria, a prática e as experiências anteriores está diretamente ligada às aprendizagens significativas, que fazem parte tanto da formação do professor quanto da formação do aluno da educação básica. Se a busca pela transposição das teorias aprendidas nos bancos escolares para as práticas na vida cotidiana é um ponto importante para que as aprendizagens sejam efetivamente significativas para as crianças, essa também deve ser a lógica da formação de professores (CARAMORI, 2016, p. 1037).
\end{abstract}

Torna-se importante o fornecimento de condições sociais e psicológicas às famílias para que a inclusão seja realizada de maneira efetiva, sem graves intercorrências. Educação inclusiva não somente está ligada às questões sociais, culturais, mas também envolvem os sujeitos e atores com as mais variadas situações, tais como: sujeitos vulneráveis socialmente e economicamente; deficiência física e intelectual; sexualidade, etc. A educação inclusiva na 
perspectiva do ensino e aprendizagem requer um olhar com mais criticidade, aplicabilidade das políticas públicas, participação dos atores sociais envolvidos, da sociedade em geral, da escola e do Estado.

\section{A educação à distância na educação especial}

Em se tratando da correlação entre a EaD com a Educação Especial no Brasil, na Lei de Diretrizes e Bases da Educação, Decreto 5.622, de 19 de dezembro de 2005, o Artigo 2 afirma que a educação à distância poderá ser aplicada também na educação especial, respeitadas as atividades legais e pertinentes. Mas, a literatura é escassa quando se trata da aplicação da modalidade à distância na educação especial.

Porém, o uso da $\mathrm{EaD}$ como meio de formação complementar do professor para a educação especial tem se tornado crescente nos últimos anos, devido ao desenvolvimento dessa modalidade de ensino, assim como o a necessidade do preparo do profissional da educação para a educação especial e inclusão escolar.

Rodrigues e Capellini (2012) tiveram como objetivo levantar e analisar dados em relação à utilização da educação à distância para formação continuada de professores quanto ao processo de inclusão da pessoa com deficiência. Ao desenvolverem o estudo fizeram o seguinte questionamento - Será que a modalidade de Educação à Distância contribui para a formação inicial de educadores quanto ao processo de inclusão da pessoa com deficiência? Os autores realizaram uma pesquisa de campo descritiva, utilizando questionário semiestruturado composto por 17 questões mistas. O questionário foi disponibilizado no ambiente de educação à distância (TelEduc) de uma disciplina específica do curso à distância 'Práticas de Educação Especial e Inclusiva na área de Deficiência Mental (Intelectual)', promovido pelo MEC e UNESP - Bauru em parceria com as Secretarias de Educação Municipais e Estaduais do território nacional.

Participaram do estudo 182 alunos, sendo equivalente a $62 \%$ dos concluintes do curso à distância. A maioria dos participantes ocupava a função de professor, sendo assim, segundo os autores, atendia a proposta de formação continuada do Ministério da Educação do país que, por meio de ferramentas de Educação à distância capacita educadores para atuar no processo de inclusão da pessoa com deficiência.

Como resultado, 96\% consideram que a modalidade de Educação à Distância atende, inicialmente, à formação continuada de professores para o processo de inclusão da pessoa com 
deficiência. Outros resultados também foram discutidos, como acesso a computador com internet, número de acessos ao ambiente virtual, sensação de abandono do aluno por parte do tutor da disciplina. Os autores defendem que a Educação à Distância contribui para a formação continuada dos educadores no processo de inclusão da pessoa com deficiência, e ressaltam ainda a importância da estruturação de um curso em que os participantes tenham a sensação de estarem sendo assistidos em todo o tempo e possam contar sempre com o tutor da disciplina.

Acredita-se que a educação à distância seja uma alternativa para a formação continuada de professores da educação especial, facilitando a questão de espaço e tempo e possibilitando um diferencial no processo de formação, assim como afirmam Benisterro e Schlünzen Junior (2005) em um estudo de revisão sobre a formação continuada de professores e as TICs na profissionalização de pessoas com deficiência visual.

Borowsky (2010) buscou investigar os fundamentos teóricos do Curso de Aperfeiçoamento de Professores para o Atendimento Educacional Especializado, produzidas pela Secretaria de Educação Especial do MEC e integrantes do Programa Educação Inclusiva: Direito à diversidade, no ano de 2007. O Curso continha em sua totalidade carga horária de 180 horas, sendo que 156 horas eram ministradas por meio da educação à distância e apenas 24 horas eram presenciais. A autora questiona a eficácia do uso da educação à distância para a formação complementar do professor da educação especial. Pontua ainda que a educação à distância é utilizada para garantir custos menores ao Estado, que busca atingir em pouco tempo milhares de professores. Contudo, ainda assim a modalidade à distância é considerada adequada, apesar das carências existentes em relação ao material teórico ofertado.

Não se encontrou estudos em bases de dados nacionais que tratavam o uso da Educação à Distância diretamente com o aluno portador de deficiência.

\section{Considerações finais}

A educação à distância é uma modalidade de educação em constante crescimento no Brasil e no mundo, pois a sua facilidade e a garantia de um programa de ensino/aprendizagem tem feito com que essa modalidade cresça expressivamente nos últimos anos.

Sabe-se que a educação especial e o processo de inclusão escolar é um processo ainda em andamento em nosso país, possuindo algumas dificuldades, assim como a necessidade de adequação em vários pontos para que aconteça de maneira positiva, sendo um deles a formação 
continuada do professor da educação especial, como também na formação inicial mediante a disciplinas direcionadas para a demanda.

Observa-se que o ensino e aprendizagem têm suas estratégias e contam com políticas pedagógicas diferenciadas de acordo com a instituição, mas, por outro lado, a formação de professores no desenvolvimento das habilidades e competências ainda requer um olhar mais crítico quanto aos currículos dos curso de graduação e licenciatura para formar educadores para atuar com a educação inclusiva, sendo assim, observar a formação desse sujeito e inseri-lo no mercado de trabalho, tanto no setor privado quanto público, ainda requer mais atenção. Notase que os professores e estudantes falam sobre a inclusão, mas de fato deve-se aprimorar as habilidades e competências da sociedade como um todo nessa questão.

A concepção dos professores, segmento envolvido diretamente no processo, não condiz com os princípios inclusivos, uma vez que não se percebem como agentes da mudança, o que aponta para a necessidade de políticas de formação que institucionalizem, definindo tempo e espaço, uma formação em serviço que considere a realidade da escola, do professor e dos alunos ali matriculados. A prática pedagógica inclusiva, aquela que responde às necessidades variadas dos alunos, precisa ser construída: não sabemos trabalhar com todos os alunos porque historicamente a escola selecionou e homogeneizou o grupo de educandos e seus modelos pedagógicos.

É preciso criar uma cultura de colaboração, envolvendo professores comuns, professores especializados, gestão da escola, família, parceiros da comunidade, enfim, todos os recursos humanos capazes de oferecer à escola e aos alunos condições plenas de desenvolvimento (CARNEIRO; UEHARA, 2016).

A educação à distância tem sido um meio utilizado para a formação do professor da educação especial e tem se mostrado uma boa alternativa para o desenvolvimento das habilidades e competências; mas, ainda, existem algumas dúvidas sobre a modalidade à distância na educação especial, assim como em qualquer outra modalidade de ensino à distância, destacamos principalmente como a $\mathrm{EaD}$ realmente pode contribuir na formação do sujeito com alguma deficiência e se os profissionais da educação estão preparados para utilizar as possibilidades que as tecnologias promovem no processo de ensino e aprendizagem, haja vista que na educação ainda observamos que alguns profissionais tem dificuldades para interagir com a tecnologia e os sujeitos no cenário educacional.

Diante dos textos analisados, consideramos que o campo e objeto das pesquisas - EaD, tecnologias, formação continuada do professor, conceitos sobre a $\mathrm{EaD}$ - são explicitas, mas ainda não há uma realidade voltada para a formação do sujeito com alguma deficiência - e 
entendemos aqui toda e qualquer deficiência, seja mental (intelectual, cognitiva), deficiência visual e auditiva. Logo, consideramos ainda a importância de estudos que investiguem o uso da educação à distância diretamente com o aluno portador de deficiência, independentemente do nível de ensino, técnico, profissionalizante ou superior, assim como as modificações nessa modalidade de ensino para atender aos alunos da educação especial.

\section{Referências}

ALMEIDA, W. A. Educação especial: desafios e conquistas no processo de inclusão. Revista Igapó, 2008.

ALVES, L. Educação à Distância: Conceitos e história no Brasil e no mundo. RBAAD, Associação Brasileira de Educação à Distância. v. 10, 2011.

ARAÚJO, D. A.; LIMA, E. D. R. P. Dificuldades enfrentadas pelo cuidador na inclusão escolar de crianças com paralisia cerebral. Educação em Revista, Belo Horizonte, v. 27, n.03, p. 281-304, dez., 2011.

BELLONI, M.L. Ensaio sobre a educação à distância no Brasil. Educação \& Sociedade, v.23, n. 78, 2002.

BENISTERRO, R. H.; SCHLÜNZEN JUNIOR, K. A formação continuada de educadores e as TIC na profissionalização de pessoas com deficiência visual. Revista Educação Especial, n. 25, 2005.

BIZELLI, J. L.; CUNHA DARIDO, M. O processo de construção da Unesp corporativa. Revista Ibero-Americana de Estudos em Educação, Araraquara, v.8, n.2, 2013. Disponível em: <http://seer.fclar.unesp.br/iberoamericana/article/view/6540/4815>. Acesso em: 20 mar. 2017.

BOROWSKI, F. Formação continuada de professores: análise do Curso de Aperfeiçoamento de Professores para o Atendimento Educacional Especializado. 2010. Dissertação (Mestrado em Educação) - Universidade Federal de Santa Catarina, Florianópolis, 2010.

BRASIL. Constituição Federal de 1988. Disponível em: <http://www.planalto.gov.br/ccivil_03/constituicao/constituicaocompilado.htm>. Acesso em: 25 fev. 2016.

BRASIL. Decreto 5.622, de 19 de dezembro de 2005. Regulamenta o artigo 80 da Lei no 9.394, de 20 de dezembro de 1996, que estabelece as diretrizes e bases da educação nacional. Diário Oficial [da] República Federativa do Brasil. Brasília, DF, 20 dez. 2005. 
Disponível em: <http://www.planalᄀto.gov.br/ccivil_03/_Ato2004-2006/2005/Decreto/ D5622.htm>. Acesso em: 25 fev. 2016.

BRASIL. Lei no 9.394, de 20 de dezembro de 1996. Estabelece as diretrizes e bases da educação nacional. Presidência da República da Casa Civil. Brasília, 20 de dez 1996. Disponível em : < http://www.planalto.gov.br/ccivil_03/leis/19394.htm>. Acesso em: 25 fev. 2016.

BRASIL. Ministério da Educação. Portaria ministerial n. 1.793, de 27 de dezembro de 1994. Brasília, DF, 1994a. Disponível em: <http://portal.mec.gov.br/seesp/arquivos/pdf/port1793.pdf>. Acesso em: 25 fev. 2016.

CAMACHO, A. C. L. F. Análise das publicações nacionais sobre educação á distância na enfermagem. Rev. Bras. Enferm, v. 62, n. 4, Brasília, 2009.

CANTINI, M. C., et al. O Desafio do professor frente as novas tecnologias. 2015. Disponível em: <http://www.pucpr.br/eventos/educere/educere2006/anaisEvento/docs/CI-081-TC.pdf>. Acesso em: 24 abr. 2017.

CARAMORI, P. M. Formação em serviço de professores comuns e especializados e suas implicações na prática: uma experiência de consultoria colaborativa. Revista IberoAmericana de Estudos em Educação, v. 11, n. esp. 2, p.1034-1047, 2016. Disponível em: <https://dx.doi.org/10.21723/riaee.v11.esp2.p1034-1047>. Acesso em: 30 mar. 2017.

CARDOSO, Paulino de Jesus Francisco et al. Formação continuada em educação das relações étnico-raciais: o(a) professor(a) tutor(a) na construção do conhecimento. Revista Ibero-Americana de Estudos em Educação, Araraquara, v. 11, n. 3, p.1389-1408, 2016. Disponível em: Disponível em: <https://dx.doi.org/10.21723/riaee.v11.n3.8018>. Acesso em: 20 jan. 2017.

CARNEIRO, R. U. C.; UEHARA, F. A inclusão de alunos público-alvo da educação especial no ensino fundamental I através do olhar dos professores. Revista IberoAmericana de Estudos em Educação, Araraquara, v. 11, n. esp. 2, p.911-934, 2016. Disponível em:<http://dx.doi.org/10.21723/riaee.v11.esp2.p911-934>. Acesso em: 20 abr. 2017.

COSTA, S. do N.; ALVES, L. R. O polo de apoio presencial como espaço de gestão e autonomia na EaD. As contingências na Gestão da EaD. Revista on line de Política e Gestão Educacional, Araraquara, v. 17, n. 1, 2014. Disponível em: < http://seer.fclar.unesp.br/rpge/article/view/9371/6222>. Acesso em: 20 jan. 2017.

DEMO, P. Nova mídia e educação: incluir na sociedade do conhecimento. UNB, 2005. <http://telecongresso.sesi.org.br/templates/capa/TextoBase_4Telecongresso.doc.>. Acesso em: 10 abr. 2017.

DOWBOR, L.; SACHS, I.; LOPES, C. Riscos e oportunidades em tempo de mudança. Instituto Paulo Freire. São Paulo, 2010. 
FACHINETTI, T. A. et al. O trabalho pedagógico para alunos público-alvo da educação especial: investigando a inclusão na educação infantil. Revista Ibero-Americana de Estudos em Educação, v. 11, n. esp. 2, p.861-880, 2016. Disponível em: <https://dx.doi.org/10.21723/riaee.v11.esp2.p861-880>. Acesso em: 30 abr. 2017.

GARLET, F. R.; MINUZZI, R. de F. B. A imagem no contexto EaD: problematizações a partir da cultura visual. Revista Ibero-Americana de Estudos em Educação, Araraquara, $\quad$ v. $\quad 9, \quad$ n.1, $2014 . \quad$ Disponível $\quad$ em: <http://seer.fclar.unesp.br/iberoamericana/article/view/6865/4946>. Acesso em: 10 fev. 2017.

GIOLO, J. A educação a distância e a formação de professores. Edu. Soc., Campinas, v.29, n. 105, p. 1211-1234, set/dez., 2008.

HOHENDORFF, Jean Von. Como escrever um artigo de revisão de literatura. In: KOLLER, S. H.; COUTO, M. C. P. de P.; HOHENDORFF, J. V. Manual de produção científica. (Organizadores). Porto Alegre: Penso, 2014.

KASSAR, M. C. M. Educação especial no Brasil: desigualdades e desafios no reconhecimento da diversidade. Educação \& Sociedade, v.33, n. 120, 2012.

LAPA, A. B.; BELLONI, M. L. Educação à distância como mídia educação. Perspectiva, v. 30, n.1, 2012.

LEMES, S. de S.; MAIA, A. C. B.; YAMAUTI, V. L. dos R. Educação sexual na modalidade EaD: um estudo exploratório. Revista on line de Política e Gestão Educacional, Araraquara, v. 18, n. 1, 2015. Disponível em: <http://seer.fclar.unesp.br/rpge/article/view/9378/6229>. Acesso em: 10 fev. 2017.

LUIZ, F. M. R; NASCIMENTO, L. C. Inclusão escolar de crianças com síndrome de down: experiências contadas pelas famílias. Rev. Bras. Ed. Esp., Marília, v.18, n.1, p. 127-140, Jan.-Mar., 2012.

MANTOAN, M. T. E. A educação especial no Brasil: da exclusão à inclusão escolar. 2006. Disponível em: <http://www.lite.fe.unicamp.br/cursos/nt/ta1.3.htm>. Acesso em 25 de fev de 2015.

MATTOS, M. O. de.; BIZELLI, J. L. Atendimento educacional para alunos com necessidades educativas especiais na Espanha. Revista Ibero-Americana de Estudos em Educação, v. 11, n. esp. 2, p.1059-1071, 2016. Disponível em: <https://dx.doi.org/10.21723/riaee.v11.esp2.p1059-1071>. Acesso em: 30 abr. 2017. MENDES, E. G. A radicalização do debate sobre inclusão escolar no Brasil. Revista Brasileira de Educação, v. 11 n. 33, 2006.

MENDES, E. G. Breve histórico da educação especial no Brasil. Revista Educación y Pedagogía, v. 22, n. 57, mayo-agosto, 2010.

MORAM, J. M. Modelos e avaliação do ensino superior à distância no Brasil. ETD Educação Temática Digital, v.10, n.2, p.54-70, jun. 2009. 
MORAN, J. M. O que é educação a distância? Disponível em: <http://umbu.ied.dcc.ufmg.br/moodle/file.php/117/Nivel_0/Conteudo/O_que_educao_a _distancia.pdf>. Acesso em: 25 fev. 2016.

MUGNOL, M. A educação a distância no Brasil: conceitos e fundamentos. Rev. Diálogo Educ., v. 9, n. 27, 2009.

RODRIGUES, L. M. B. C; CAPELLINI, V. L. M. S. A educação à distância e formação continuada do professor. Rev. Bras. Ed. Esp., Marília, v. 18, n. 4, p. 615-628, out-dez, 2012.

SANTOS, A. M. Z.; ALMEIDA, S. do C. D. de. Gestão do conhecimento na educação a distância: propondo competências para o nível operacional. Revista Ibero-Americana de Estudos em Educação, Araraquara, v.12, n.1, p. 332-349, 2017. Disponível em: <http://dx.doi.org/10.21723/riaee.v12.n1.8282>.Acesso em: 20 jan. 2017.

TEZANI, T. C. R. Discutindo a EaD no ensino superior: dando voz aos alunos. Revista Ibero-Americana de Estudos em Educação, Araraquara, v. 9, n.1, 2014. Disponível em: <http://seer.fclar.unesp.br/iberoamericana/article/view/6856/4937>. Acesso em: 10 fev. 2017.

VOLPATO, S. M.; SANTOS CRUZ, J. A. A qualidade dos conteúdos e a eficiência das TICs no processo de aprendizagem: uma percepção dos estudantes em EaD. Revista Tecnologias na Educação, ano 8, n. 14, jul/2016. Disponível em: <https://goo.gl/MTTcjY>. Acesso em: 20 mar. 2017.

\section{Como referenciar este artigo}

SARTORI, Dulcegleika Villas Boas et al. Estudo analítico de publicações sobre EaD na educação especial como ferramenta pedagógica. Revista Ibero-Americana de Estudos em Educação, Araraquara, v. 12, n. 2, p. 862-883, 2017. Disponível em: <http://dx.doi.org/10.21723/riaee.v12.n2.9825>. E-ISSN: 1982-5587.

Submetido em: 10/02/2017

Aprovação final em: 20/05/2017 